\title{
Health care practitioners' responsibility to address intimate partner violence related to the COVID-19 pandemic
}

\author{
Nori L. Bradley MD MSc, Ashley M. DiPasquale MD, Kaitlyn Dillabough BSc, Prism S. Schneider MD PhD
}

Cite as: CMAJ 2020 June 1;192:E609-10. doi: 10.1503/cmaj.200634; early-released May 1, 2020

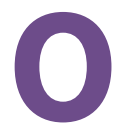

n Mar. 27, 2020, the United Nations issued a statement warning that rates of widespread intimate partner violence (IPV) will increase owing to the coronavirus disease 2019 (COVID-19) pandemic, including intimate partner femicides. ${ }^{1}$ Measures to minimize the spread of severe acute respiratory syndrome coronavirus 2 (SARS-CoV-2) reinforce environments that facilitate behaviours used by one person within an intimate relationship to exert power over and inflict physical, psychological or sexual harm on another. ${ }^{2}$ The stress of confinement, financial uncertainty, attitudes about gender roles and a desire for control during disasters all contribute to an increased risk of IPV.,34

During their recent lockdowns, China, Italy and Spain reported a substantial increase in calls to IPV emergency support lines. ${ }^{5}$ Areas of the United Kingdom and France have seen increases of $20 \%$ and $30 \%$, respectively, in police reports regarding IPV. In Canada, calls to the Vancouver Battered Women's Support Services have tripled, ${ }^{6}$ while in Alberta, specialized crisis lines for IPV have seen a 30\%-50\% increase in calls. In Ontario, the York and Durham Regional Police Departments reported a $22 \%$ increase in domestic incidents and sexual assault reports. ${ }^{7}$ Health care providers, although facing the need to learn many new skills related to COVID-19, must also maintain awareness of IPV, seek opportunities for self-education, develop strategies for discussing IPV and become familiar with currently available local resources for patient referral.

Intimate partner violence is already the most common cause of nonfatal injury to women worldwide. ${ }^{3}$ Even in the absence of a public health emergency, women have a 30\% estimated lifetime prevalence of physical and sexual IPV. ${ }^{2}$ Worldwide, a woman is killed by their intimate partner every 6 days. ${ }^{7}$ Health care professionals frequently encounter victims of IPV. One in 3 women presenting to the emergency department after a trauma have been injured by their partner, and 1 in 6 women presenting to an orthopedic fracture clinic have experienced IPV in the previous 12 months. ${ }^{8}$ Of women murdered by their intimate partner, $45 \%$ presented to a health care professional for treatment of an IPV injury in the 2 years before their death. ${ }^{3}$

Identified risk indicators for IPV include lower socioeconomic status, inadequate social supports, low education level, substance

\section{KEY POINTS}

- Rates of intimate partner violence (IPV) have increased and will remain an important health care concern as a result of the economic impact of the pandemic and the social distancing measures required to limit the health system burden of coronavirus disease 2019.

- Any health care provider who treats patients with injuries should become comfortable asking about IPV and make themselves aware of local resources available for referral.

- "Safe word" and "Signal for Help" campaigns have been launched to facilitate discreet requests for IPV resources in the setting of increased numbers of telemedicine appointments.

- Validated online resources are available to help health care providers increase their knowledge and comfort with identification and support for patients experiencing IPV.

abuse, mental illness, younger age, unintended pregnancy, financial dependency and employment status. ${ }^{4,9}$ However, IPV affects all races, ethnicities, socioeconomic strata, ages and relationship statuses. ${ }^{8}$ Because of discrimination or prejudgment, individuals who have experienced IPV may be overlooked. ${ }^{2}$

Head and neck trauma and upper extremity injuries are the most common physical health care presentations related to IPV. ${ }^{3}$ Unfortunately, only $14 \%$ of patients presenting to health care practitioners with IPV-related injuries are asked questions to identify IPV and initiate support. ${ }^{9}$ For patients in whom the health care practitioner suspects IPV, best evidence supports direct questioning about IPV in a private environment. ${ }^{9}$ Most women do not offer relevant information themselves. ${ }^{9}$ The onus is on health practitioners to begin the conversation with patients who may have experienced IPV. The American College of Surgeons Statement on IPV calls on surgeons "not only to care for our patient's immediate injuries, but also to refer patients to appropriate resources and follow-up for IPV." ${ }^{10}$ The Canadian and American Orthopaedic Associations also encourage members to take steps to educate themselves about IPV, identify IPV and offer patient assistance. ${ }^{11}$

Validated tools and resources exist to support physicians in initiating new IPV identification and support practices and programs where 
none exist currently. The EDUCATE program (www.ipveducate.com/ the-educate-training-program) is a multimodal training platform that provides resources for orthopedic surgeons and other practitioners working with patients who present with trauma in order to promote knowledge and comfort with IPV identification and support. ${ }^{8}$ REAL Talk (https://realtalk.sagesse.org/) is an Alberta initiative that provides online training and workshops for health practitioners and the public to help recognize, empathize, ask and listen to individuals who have experienced IPV. Women's College Hospital in Toronto hosts the Domestic Violence Education Program (http://dveducation.ca), with online, self-paced modules to achieve competency in clinically relevant aspects of IPV. The American College of Surgeons' Statement on Intimate Partner Violence advocates using the SAFE technique (www.facs.org/about-acs/statements/115-partner-violence). ${ }^{10}$

Uncertainty about how to manage disclosure of IPV is a common barrier to asking about IPV. ${ }^{11}$ Educational platforms, such as EDUCATE, can improve readiness and confidence in managing a disclosure. ${ }^{8}$ REAL Talk, the World Health Organization clinical handbook $^{12}$ and the EDUCATE program all provide training on how to address immediate patient safety, including creation of a safety plan, referral to a social worker and provision of appropriate resources.

The COVID-19 pandemic creates a unique challenge for IPV identification and support in the out-patient setting. Many physicians and surgeons have transitioned to telemedicine follow-ups to maintain physical distancing. However, during isolation at home, phone or videoconference follow-up with patients often occurs in an environment where the perpetrator of violence is also present. A Canadian "safe word" campaign has been launched for patients who cannot be interviewed in private, following a European initiative for patients to inform health care workers if they are at risk of IPV. ${ }^{13}$ The Signal for Help campaign has a hand signal to allow for a silent request for help during telemedicine (https://canadianwomen.org/signal-for-help/). The goal is to provide discreet communication strategies for patients who wish to request assistance. If a patient uses the safe word or shows the signal for help, health practitioners should offer support, including referral to local IPV support services. Signal for Help offers toolkits and strategies for safe check-in on its website.

The United Nations has urged governments to continue combatting IPV in the time of COVID-19, ensuring continued access to legal services, safe shelters and support phone lines for individuals who have experienced IPV. ${ }^{1}$ The Canadian federal government announced an extra \$40 million in funding for women's shelters and sexual assault centres, and $\$ 10$ million for Indigenous women and children fleeing violence. ${ }^{14}$ Thus, Canada's women's shelters will remain open, with COVID-19 screening programs in place. However, IPV identification and support strategies must also include options such as online chats and texting services to provide avenues of safe communication during this time of confinement. Even after the pandemic ends, the economic downturn will continue for months, and with it an increased risk of IPV. In the 9 months after Hurricane Katrina, women in the affected region experienced violence by a partner at more than 3 times the annual rate in the United States, and intimate partner rape rose 16 -fold. ${ }^{4}$

All health care providers must be prepared to address the increase in IPV associated with the COVID-19 pandemic and its aftermath.

\section{References}

1. States must combat domestic violence in the context of COVID-19 lockdowns - UN rights expert [press release]. Geneva: Office of the United Nations High Commissioner for Human Rights; 2020 Mar. 27. Available: www.ohchr.org/EN/ NewsEvents/Pages/DisplayNews.aspx?NewsID=25749\&LangLa=E (accessed 2020 Apr. 1).

2. Garcia-Moreno C, Hansen HAFM, Ellsberg M, et al. Prevalence of intimate partner violence: findings from the WHO multi-country study on women's health and domestic violence. Lancet 2006;368:1260-9.

3. Bhandari M, Dosanjh S, Tornetta P III, et al.; Violence Against Women Health Research Collaborative. Musculoskeletal manifestations of physical abuse after intimate partner violence. J Trauma 2006;61:1473-9.

4. World disasters report 2007 - focus on discrimination. Geneva: International Federation of Red Cross; 2007. Available: www.ifrc.org/en/publications-and -reports/world-disasters-report/wdr2007/ (accessed 2020 Apr. 1).

5. Taub A. A new COVID-19 crisis: domestic abuse rises worldwide. The New York Times 2020 Apr. 6. Available: www.nytimes.com/2020/04/06/world/coronavirus -domestic-violence.html (accessed 2020 Apr. 22).

6. Daya R, Azpirir J. Calls to Vancouver domestic-violence crisis line spike $300 \%$ amid COVID-19 pandemic. Global News 2020 Apr. 7. Available: https://globalnews. ca/news/6789403/domestic-violence-coronavirus/ (accessed 2020 Apr. 7).

7. Amin F. Domestic violence calls surge during pandemic. City News [Toronto] 2020 Apr. 8. Available: https://toronto.citynews.ca/2020/04/08/domestic -violence-calls-surge-during-coronavirus-pandemic/ (accessed $2020 \mathrm{Apr}$. 22).

8. EDUCATE Investigators. Novel education program improves readiness to manage intimate partner violence in the fracture clinic: a pretest-posttest study. CMAJ Open 2018;6:E628-36.

9. PRAISE Investigators; Sprague S, Bhandari M, Della Rocca GJ, et al. Prevalence of abuse and intimate partner violence surgical evaluation (PRAISE) in orthopaedic fracture clinics: a multinational prevalence study. Lancet 2013;382:866-76.

10. Statement on intimate partner violence. Chicago: American College of Surgeons; updated 2018 June 1. Available: www.facs.org/about-acs/statements/115-partner -violence (accessed 2020 Apr. 1).

11. Della Rocca GJ, Tornetta P III, Schneider PS, et al. Intimate partner violence and orthopaedics: AOA critical issues. J Bone Joint Surg Am 2019;101:e62.

12. Health care for women subjected to intimate partner violence or sexual violence: a clinical handbook. Geneva: World Health Organization. Available: https://apps.who.int/iris/bitstream/handle/10665/136101/WHO_RHR_14.26_ eng.pdf?sequence=1 (accessed 2020 Apr. 22).

13. Higgins N. Coronavirus: when home gets violent under lockdown in Europe. $B B C$ News [Brussels] 2020 Apr. 13. Available: www.bbc.com/news/world-europe -52216966 (accessed 2020 Apr. 27).

14. Canada announces support to those experiencing homelessness and women fleeing gender-based violence during the coronavirus disease (COVID-19) pandemic [news release]. 2020 Apr. 4. Gatineau (QC): Employment and Social Development Canada. Available:www.canada.ca/en/employment-social-development/news/ 2020/04/canada-announces-support-to-those-experiencing-homelessness-and -women-fleeing-gender-based-violence-during-the-coronavirus-disease-covid-19 -pandemic.html (accessed 2020 Apr. 4).

\section{Competing interests: None declared.}

This article has been peer reviewed.

Affiliations: Department of Surgery (Bradley, DiPasquale), University of Alberta, Edmonton, Alta.; Department of Critical Care Medicine (Bradley), The University of British Columbia, Vancouver, BC; Department of Surgery (Dillabough) and Departments of Surgery and Community Health Sciences (Schneider), University of Calgary Cumming School of Medicine, Calgary, Alta.

Contributors: All of the authors contributed to the conception and design of the work, drafted the manuscript, revised it critically for important intellectual content, gave final approval of the version to be published and agreed to be accountable for all aspects of the work.

Correspondence to: Prism Schneider, prism.schneider@albertahealthservices.ca 